\title{
Does farm animals experience emotions and feelings?
}

\author{
Miguel Machado ID . Iran José Oliveira da Silva iD
}

M Machado (Corresponding author) - IJO Silva

Ambience Research Group (NUPEA), Departament of

Biosystems Engeneering, University of São Paulo (USP), Av.

Pádua Dias, 11, 13418-900, Piracicaba, São Paulo, Brazil.

email: miguelmac89@gmail.com

Received: April 30, 2019 • Revised: June 04, 2019 • Accepted: June 04, 2019

\begin{abstract}
In recent years, there has been a great increase in the interest of "emotion" and how it can be studied and translated from animals. Emotions arise when the brain receives an external stimulus, while the feeling is a response to emotion and concerns how the individual feels before that emotion. Emotional states do not exist to be locked within an individual. Emotions are expressed in some way and have great importance for the welfare of animals, especially within the farm animal production chains. The affective side of emotions is more difficult to be studied, however, it takes an effort to evaluate what is observable, registrable and measurable: behavioral and physiological measures that may indicate positive and negative emotional states. It is possible to use behavioral and even physiological information to analyze the feeling and, especially, the immediate emotion that triggers it in animals. The aim of this article is to review the concepts and researches on emotions and feelings in farm animals that may be related to the expression of emotions.
\end{abstract}

Keywords: expression, negative stimulus, positive stimulus, welfare

\section{Introduction}

Initially, when we speak of emotional states in animals, it is important to define that the expression of emotion comes from a stimulus that will result in an emotion.

In this vision, the ACTION (stimulus) will promote a REACTION (emotion-feeling). In psychology, stimulus is a pattern recorded by sense organs that is processed in a complex way by the brain, and leads to different emotions and feelings (Paul and Mendl 2018). However, for behaviorism and classical conditioning, the stimulus is the basis for behavior (Amd et al 2017).

In this way, animals are directed to stimuli and repeat behaviors that they judge as positive, and avoid negative ones (Rolls 2013). Emotion caused by stimuli of a positive or negative nature is often described based on two characteristics: valence (how negative or positive the emotion is) and the level of arousal involved (high or low) (Russell 2003).

Thus, it is possible to understand how (how positive or negative) animals experience their activities and situations, and how calm or excited they are (Figure 1). These external stimuli, therefore, can be considered by the animals as pleasurable, bad or even neutral.

Emotional states occur in response to stimuli or situations that are potentially rewarding or punitive. Reward and punishment, therefore, are at the center of all emotional states and determine their valence. Gratifying or punitive stimuli in nature include those who improve fitness (rewarders - food, water, shelter, partners) and those who threaten fitness (punishers - predator attack, heat stress, etc.) (Mendl et al 2010; Rolls 2013).

It is believed that the responses of different animal species to these stimuli have developed over evolutionary time and act as mechanisms that guide and coordinate the organism to achieve two main objectives of survival: maximize the acquisition of rewards that increase fitness and minimize exposure to punitive threats (Mendl et al 2010).

Therefore, a positive stimulus works as a reward and may be all that an animal will seek to achieve. On the other hand, a negative stimulus is synonymous with punishment, and represents everything an animal will avoid or try to get rid of. An example of a positive stimulus is stroking of body parts, which provokes emotions of positive valence. A negative stimulus can be represented by the sound of a noisy vehicle, which causes fear (Rolls 2013).

Figure 1, therefore, indicates which stimuli are received as positive and negative by dairy cows. The positive effects of stroking and tactile contact are already used to improve man-animal interactions. Gentle handling and stroking in dairy cows and heifers contribute to lowering the fear of humans, and reduce cortisol levels and heart rate during mny procedures (Proctor and Carder 2014; Proctor and Carder 2015; Lambert and Carder 2019). 
Previous studies have demonstrated the effects of tactile stimulation on the human-animal relationship by stroking different parts of the body of dairy cows (Schmied et al 2008; Westerath et al 2014; Buchli et al 2017). Schmied et al (2008) studied the social interaction between adult cows and observed that $64 \%$ of the positive interactions are directed towards the neck region. In addition, according to Westerath et al (2014), being stroked by a person is considered positive for calves, and Buchili et al (2017) affirmed that the positive contact between cow-calf and man-calf, even if restricted in time, has a beneficial effect on the emotional reactivity and improves the social adaptation of the animals. With this, there is a distinction between action and reaction from positive and negative stimuli. Stimulation by caressing body areas demonstrates positive reactions and has effects similar to those found during positive social interactions between animals (Shahin 2018).

The aim of this article is to review the concepts and researches on emotions and feelings in farm animals that may be related to the expression of emotions.

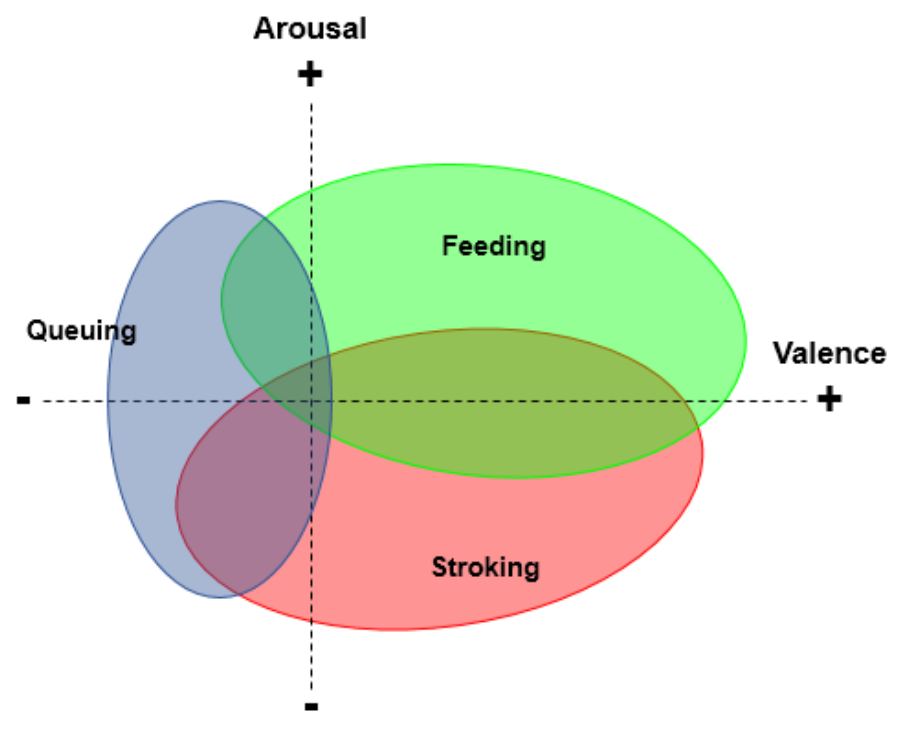

Figure 1 Representation of the diagram of level of excitation and valence caused by stimuli from feeding, stroking and queuing, in dairy cows. Adapted from Oliveira and Keeling (2018).

\section{Emotions in animals}

Emotion is a reaction to an environmental stimulus that produces both subjective experiences and significant neurobiological changes (Amaral 2007). The word derives from the Latin term "emovere", where the "e" means "outside" and "movere" means "movement". Whether it is to deal with environmental stimuli or to communicate biologically relevant social information, the emotions present several adaptive components for mammals with complex social behavior and are crucial even for their survival (Widen and Russell 2010).

In recent years there has been a great increase in interest in the subject "emotion" and how it can be studied and translated from animals, especially between neuroscientists and ethologists (Paul and Mendl 2018).

Understanding emotions in animals is important for improving well-being. In fact, the assumption that animals are sentient beings, capable of feeling emotions such as fear, frustration, and pleasure is grounded in the science of animal welfare, since an animal's ability to experience suffering is a prerequisite for this science (Spinka 2012).

For De Vere and Kuczaj (2016) emotion is a comprehensive concept that encompasses feeling, affection, and humor. It is defined as a short-term affective state caused by an event (Forkman et al 2007). In this way, they are differentiated from long-term affective states (as a state of depression), however, they are connected and one influences the other (Mendl et. al 2010).

Widen and Russell (2010) suggest the construction of two possibilities when defining emotions: the descriptive and the prescriptive. The descriptive definition is that offered by the dictionary, based on the understanding of the language. The prescriptive is a definition of the concept or construct that is used to choose the set of events that a scientific theory (in this case of emotion) intends to explain. However, this latest exposure still needs to be supported by scientific work (Paul and Mendl 2018).

Emotions do not exist to be locked inside an individual. They are expressed in some way and have great importance 
for the welfare of animals, especially within the production chains.

Animals in production systems, such as dairy cattle, live in large social groups composed of different individuals. There are indications that dairy cattle transfer emotions to each other through behavioral signs. An example of emotional transference between cattle is the process called emotional contamination that occurs when an animal is surprised by someone, an object or some sudden movement (action), and all the animals in the group react by fleeing or retreating (reaction) (Spinka 2012).

In these cases, there is a first animal that receives the stimulus, processes it and expresses the emotion, communicating the other animals (Spinka 2012). This process can multiply positive and negative emotions within the herd and therefore is of great importance for animal welfare.

Despite the importance, the relationship between emotions and animal welfare is still a rather obscure issue for science. However, with the advancement of neuroscience, scientists are coming to a consensus that animals, especially mammals, feel emotions in the same way humans do. Charles Darwin's ancient records already illustrated different body postures and facial expressions associated with fear and aggressiveness in animals. It is very likely that cows, like other mammals, experience a dynamic and varied daily emotional life (Hess and Thibault 2009; Mendl et al 2017).

The investigation of the existence of emotion in animals reveals importance of this consideration for animal welfare, however, it is still necessary to understand how these emotions can be analyzed.

The affective side of emotions is more difficult to be studied, however, it takes an effort to evaluate what is observable, recordable and measurable: behavioral and physiological measures that can indicate positive and negative emotional states (Mendl et al 2010). These measures have been examined as a "window" for animal emotions.

In addition, Coulon et al (2015) found changes in heart rate in lambs when it was approached by humans. The reduction in heart rate was observed in other studies on the positive interaction of humans with horses (Feh and Mazierès 1993; Munsters et al 2012; Greve and Dyson 2013; Janczarek et al 2018; Janczarek et al 2019; Wiśniewska et al 2019) and cattle (Schmied et al 2008; Lürzel et al 2015; Lürzel et al 2016; Lürzel et al 2018; Shahin 2018).

Traditionally, most animal welfare research focuses on negative emotions such as pain, fear, anxiety, frustration, anger, boredom, and their relationships to animal suffering and stress. However, research has developed to investigate the link between positive emotions and animal welfare (Spinka 2012; Rolls 2013; Mellor 2016; Meunier et al 2017; Mendl et al 2017; Paul and Mendl 2018).

The study of emotions in humans can be based on communication. People are aware of their emotions and can use the communicative language to express themselves. In animal studies we do not have this reference channel up to now, despite several current studies evaluate vocalization (Scheumann et al 2017; Halachmi et al 2018; Liu et al 2018; Todorov and Aviezer 2018). In any case, we need to indirectly access subjective components such as behavioral and physiological changes, which we can measured. Based on these answers, inferences can be made about the emotional states of animals (Reimert et al 2017).

Mendl et al (2010) suggested behavioral and physiological components as indicators of emotions. With this, we have that emotional states can be represented as places within a two-dimensional space (Mendl et al 2010; Paul and Mendl 2018; Oliveira and Keeling 2018), with valence (positive / negative) and arousal level (high / low). Emotional experiences can be perceived as positive or negative, rewarding or punitive, pleasurable or unpleasant, and can be represented in a two-dimensional space, as shown in the Figure 2.

There are implications of the emotion experienced by the animal on the well-being of individuals in production systems, such as stress caused by environmental factors. The actual reach of these implications needs to be studied and for this we have sought to correlate body areas such as ears, tail, eye, mouth, nostril and other areas to the expression of emotions in cattle (Proctor and Carder 2014; Frondelius et al 2015; Lambert and Carder 2017; Lambert and Carder 2019), sheep (Boissy et al 2011; Coulon et al 2015; Bellegarde et al 2017; Tamioso et al 2018; Raoult and Gygax 2018) and pigs (Reimert et al 2013; Reimert et al 2017; Camerlink et al 2018).

\section{Feelings in animals}

Feelings differ from emotions because they are less intense, longer lasting and not accompanied by intense organic manifestations (Amaral 2007). According to Broom (1998) are aspects of the biology of an individual that must have evolved over time to somehow assist their survival.

While emotions arise when the brain receives an external stimulus, the feeling is a response to emotion and concerns how the individual feels about that emotion (Figure 3).

Today, there are scientific methods to understand the subjectivity of psychological issues in animals, which provided a scientific approach to the understanding of emotional states of animals for the evaluation of well-being (Mellor 2016). Direct observation of subjective experiences is not possible, however, there are reasons to suppose that feelings exist in nonhuman animals (Ross and Mason 2017).

Similarities in the anatomy of the nervous system between species of vertebrates, and in the physiological and behavioral responses to stimuli that trigger feelings in humans, suggest a great capacity of feelings in animals (Kirkden and 
Pajor 2006; Sheng et al 2010; Allen-Hermanson 2018; Paul and Mendl 2018).

Fraser et al (1997) described three concepts of animal welfare that define it in terms of physical health, ability to express natural behaviors and feelings. These different concepts influenced the criteria used by researchers to select variables for general analysis of animal welfare status.

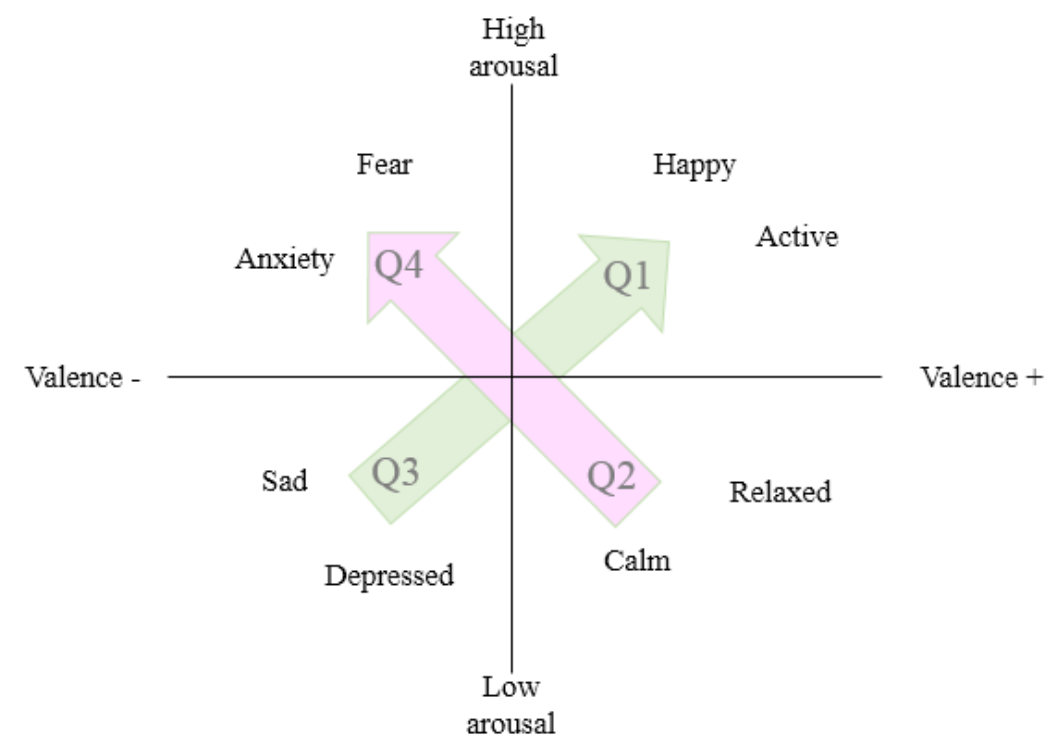

Figure 2 Two-dimensional representation of emotional experiences. Adapted from Mendl et al (2010).

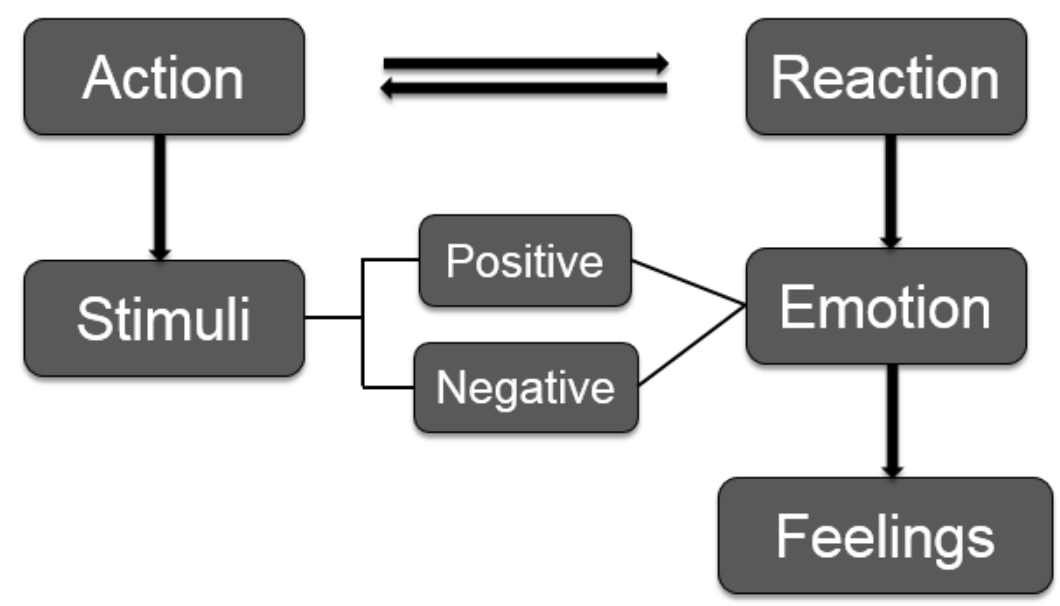

Figure 3 Relationship between stimulus, emotions and feelings.

Different research philosophies emphasize different concepts or a combination of them. Most consider feeling as an important part of animal welfare. Other lines consider it as a sole criterion. Studies that emphasize natural behaviors follow the line that feelings are irrelevant, non-measurable and that their assessment is redundant (Kirkden et al 2006).

Although it is not evident that feelings play a causal role in behavior, the opposite is supported (Veasey 2017; Wookey 2018). Even if feelings have no observable consequences, the correlation between reported feelings and behavioral responses to stimuli in humans suggests that these responses reflect the strength of the associated feelings (Cohen et al 2010). In animals, this force refers to the so-called affective state.

The term "affective state" is used to indicate the abstract experiences, feelings, and emotions that motivate animals to behave in some way towards a goal, which may be accompanied by success or failure to achieve such goals 
(Mendl et al 2017; Ahloy-Dallaire et al 2018). This motivated behavioral effect may be positive (interpreted as rewarding and pleasurable) or negative (experienced as aversive). Such effects associated with positive or negative situations reflects the animal's perception of its external environment, and generate emotions accompanied by feelings (Mellor 2015).

Thus, it is possible to use behavioral and even physiological information to analyze the feeling, and especially the immediate emotion that triggers it (AhloyDallaire et al 2018). Feelings are part of the affective life of animals and arise in response to emotions and therefore need to be studied in long-term (Paul and Mendl 2018; Weary and Robbins 2019; Beaver et al 2019).

\section{Final considerations}

It is quite likely that animals experience emotions and feelings at different levels throughout their activities. Most of these emotions are triggered by stimuli from the environment. Therefore, the relationship between environmental stimuli and emotions is important for the welfare of farm animals, such as dairy cows. The use of body indicators such as ears, tail, and face can bring important information about the emotional state of animals in production systems and function as a good tool to identify emotions. In addition, they can be measured quickly. Therefore, it is possible to develop methods for identifying emotional states and, from these responses, to stimulate positive emotional experiences in animals. However, further studies are needed to correlate body parts with the expression of positive and negative emotions.

\section{Acknowledgements}

To the Coordination of Improvement of Higher Education - Brazil (CAPES) - Financing Code 001 - for the support to carry out the project.

\section{References}

Ahloy-Dallaire J, Espinosa J, Mason G (2018) Play and optimal welfare: Does play indicate the presence of positive affective states? Behav. Processes doi: 10.1016/j.beproc.2017.11.011

Allen-Hermanson S (2018) Animal consciousness. Routledge Handb. doi:10.4324/9781315676982

Amaral VL do (2007) A vida afetiva: emoções e sentimentos. Discip. - Psicol. da Educ. 16.

Amd M, de Almeida JH, de Rose JC, Silveira CC, Pompermaier HM (2017) Effects of orientation and differential reinforcement on transitive stimulus control. Behav. Processes doi:10.1016/j.beproc.2017.08.014

Bellegarde LGA, Haskell MJ, Duvaux-ponter C, Weiss A, Boissy A, Erhard HW (2017) Face-based perception of emotions in dairy goats. Appl. Anim. Behav. Sci. doi:10.1016/j.applanim.2017.03.014

Boissy A, Aubert A, Désiré L, Greiveldinger L, Delval E, Veissier I (2011) Cognitive sciences to relate ear postures to emotions in sheep.
Anim. Welf. 20:47-56.

Broom DM (1998) Welfare, Stress, and the Evolution of Feelings. Adv. Study Behav. doi:10.1016/S0065-3454(08)60369-1

Buchli C, Raselli A, Bruckmaier R, Hillmann E (2017) Contact with cows during the young age increases social competence and lowers the cardiac stress reaction in dairy calves. Appl. Anim. Behav. Sci. doi:10.1016/j.applanim.2016.12.002

Camerlink I, Coulange E, Farish M, Baxter EM, Turner SP (2018) Facial expression as a potential measure of both intent and emotion. Sci. Rep. doi:10.1038/s41598-018-35905-3

Cohen H, Gagné MH, Hess U, Pourcher E (2010) Emotion and object processing in Parkinson's disease. Brain Cogn. Doi:10.1016/j.bandc.2010.01.001

Coulon M, Nowak R, Peyrat J, Chandèze H, Boissy A, Boivin X (2015) Do lambs perceive regular human stroking as pleasant? behavior and heart rate variability analyses. PLoS One doi:10.1371/journal.pone.0118617

de Vere AJ, Kuczaj SA (2016) Where are we in the study of animal emotions? Wiley Interdiscip. Rev. Cogn. Sci. doi:10.1002/wcs.1399

Feh C, de Mazierès J (1993) Grooming at a preferred site reduces heart rate in horses. Anim. Behav. doi:10.1006/anbe.1993.1309

Forkman B, Boissy A, Meunier-Salaün MC, Canali E, Jones RB (2007) A critical review of fear tests used on cattle, pigs, sheep, poultry and horses. Physiol. Behav. doi:10.1016/j.physbeh.2007.03.016

Fraser D, Weary DM, Pajor EA, Milligan BN (1997) A scientific conception of animal welfare that reflects ethical concerns. Anim. Welf 6:187-205.

Frondelius L, Järvenranta K, Koponen T, Mononen J (2015) The effects of body posture and temperament on heart rate variability in dairy cows. Physiol. Behav. doi:10.1016/j.physbeh.2014.12.002

Greve L, Dyson S (2013) The horse-saddle-rider interaction. Vet. J. doi:10.1016/j.tvj1.2012.10.020

Halachmi I, Guarino M, Bewle, J, Pastell M (2018) Smart Animal Agriculture: Application of Real-Time Sensors to Improve Animal Well-Being and Production. Annu. Rev. Anim. Biosci. Doi:10.1146/annurev-animal-020518-114851

Hess U, Thibault P (2009) Darwin and emotion expression. Am. Psychol. doi:10.1037/a0013386

Janczarek I, Stachurska A, Wilk I, Krakowski L, Przetacznik M, Zastrzeżyńska M, Kuna-Broniowska I (2018) Emotional excitability and behaviour of horses in response to stroking various regions of the body. Anim. Sci. J. doi:10.1111/asj.13104

Janczarek I, Wilk I, Stachurska A, Krakowski L, Liss M (2019) Cardiac activity and salivary cortisol concentration of leisure horses in response to the presence of an audience in the arena. J. Vet. Behav. Doi:10.1016/j.jveb.2018.07.007

Kirkden RD, Pajor EA (2006) Using preference, motivation and aversion tests to ask scientific questions about animals' feelings. Appl. Anim. Behav. Sci. doi:10.1016/j.applanim.2006.04.009

Lambert (Proctor) H, Carder G (2017) Looking into the eyes of a cow: Can eye whites be used as a measure of emotional state? Appl. Anim. Behav. Sci. doi:10.1016/j.applanim.2016.11.005

Lambert H, Carder G (2019) Positive and negative emotions in dairy cows: Can ear postures be used as a measure? Behav. Processes doi:10.1016/j.beproc.2018.12.007 
Liu L, Ni J, Li Y, Erasmus M, Stevenson R (2018) Assessment of heat stress in turkeys using animal vocalization analysis. IOP Publushing in ASABE. https://elibrary.asabe.org/abstract.asp?aid=49520. Acessed on: April 30, 2019

Lürzel S, Barth K, Windschnurer I, Futschik A, Waiblinger S (2018) The influence of gentle interactions with an experimenter during milking on dairy cows' avoidance distance and milk yield, flow and composition. Animal doi:10.1017/S1751731117001495

Lürzel S, Münsch C, Windschnurer I, Futschik A, Palme R, Waiblinger S (2015) The influence of gentle interactions on avoidance distance towards humans, weight gain and physiological parameters in group-housed dairy calves. Appl. Anim. Behav. Sci. doi:10.1016/j.applanim.2015.09.004

Lürzel S, Windschnurer I, Futschik A, Waiblinger S (2016) Gentle interactions decrease the fear of humans in dairy heifers independently of early experience of stroking. Appl. Anim. Behav. Sci. Doi:10.1016/j.applanim.2016.02.012

Mellor DJ (2016) Updating animalwelfare thinking: Moving beyond the "five freedoms" towards "A lifeworth living." Animals doi:10.3390/ani6030021

Mellor DJ (2015) Enhancing animal welfare by creating opportunities for positive affective engagement. N. Z. Vet. J. doi:10.1080/00480169.2014.926799

Mendl M, Burman OHP, Paul ES (2010) An integrative and functional framework for the study of animal emotion and mood. Proc. R. Soc. B Biol. Sci. doi:10.1098/rspb.2010.0303

Mendl M, Mason GJ, Paul ES (2017) Animal welfare science. APA Handb. Comp. Psychol. Perception, Learn. Cogn. doi:10.1037/0000012-035

Meunier B, Pradel P, Sloth KH, Cirié C, Delval E, Mialon MM, Veissier I (2017) Image analysis to refine measurements of dairy cow behaviour from a real-time location system. Biosyst. Eng. doi:10.1016/j.biosystemseng.2017.08.019

Munsters CCBM, Visser KEK, Van den Broek J, Sloet Van Oldruitenborgh-Oosterbaan MM (2012) The influence of challenging objects and horse-rider matching on heart rate, heart rate variability and behavioural score in riding horses. Vet. J. 192, 75-80. https://doi.org/10.1016/j.tvj1.2011.04.011

Oliveira D, Keeling LJ (2018) Routine activities and emotion in the life of dairy cows : Integrating body language into an affective state framework. Plos One. doi:10.1371/journal.pone.0195674

Paul ES, Mendl MT (2018) Animal emotion: Descriptive and prescriptive definitions and their implications for a comparative perspective. Appl. Anim. Behav. Sci. doi:10.1016/j.applanim.2018.01.008

Proctor HS, Carder G (2015) Measuring positive emotions in cows: Do visible eye whites tell us anything? Physiol. Behav. doi:10.1016/j.physbeh.2015.04.011

Proctor HS, Carder G (2014) Can ear postures reliably measure the positive emotional state of cows? Appl. Anim. Behav. Sci. doi:10.1016/j.applanim.2014.09.015

Raoult CMC, Gygax L (2018) Valence and intensity of video stimuli of dogs and conspecifics in sheep: Approach-avoidance, operant response, and attention. Animals doi:10.3390/ani8070121

Reimert I, Bolhuis JE, Kemp B, Rodenburg TB (2013) Indicators of positive and negative emotions and emotional contagion in pigs. Physiol. Behav. doi:10.1016/j.physbeh.2012.11.002
Reimert I, Fong S, Rodenburg TB, Bolhuis JE (2017) Emotional states and emotional contagion in pigs after exposure to a positive and negative treatment. Appl. Anim. Behav. Sci. doi:10.1016/j.applanim.2017.03.009

Rolls ET (2013) What are emotional states, and why do we have them? Emot. Rev. doi:10.1177/1754073913477514

Ross M, Mason GJ (2017) The effects of preferred natural stimuli on humans' affective states, physiological stress and mental health, and the potential implications for well-being in captive animals. Neurosci. Biobehav. Rev. doi:10.1016/j.neubiorev.2017.09.012

Russell JA (2003) Core Affect and the Psychological Construction of Emotion. Psychol. Rev. doi:10.1037/0033-295X.110.1.145

Scheumann M, Hasting AS, Zimmermann E, Kotz SA (2017) Human Novelty Response to Emotional Animal Vocalizations: Effects of Phylogeny and Familiarity. Front. Behav. Neurosci. doi:10.3389/fnbeh.2017.00204

Schmied C, Waiblinger S, Scharl T, Leisch F, Boivin X (2008) Stroking of different body regions by a human: Effects on behaviour and heart rate of dairy cows. Appl. Anim. Behav. Sci. doi:10.1016/j.applanim.2007.01.013

Shahin M (2018) The effects of positive human contact by tactile stimulation on dairy cows with different personalities. Appl. Anim. Behav. Sci. doi:10.1016/j.applanim.2018.04.004

Sheng SR, Wang XY, Xu HZ, Zhu GQ, Zhou YF (2010) Anatomy of large animal spines and its comparison to the human spine: A systematic review. Eur. Spine J. doi:10.1007/s00586-009-1192-5

Špinka M (2012) Social dimension of emotions and its implication for animal welfare. Appl. Anim. Behav. Sci. doi:10.1016/j.applanim.2012.02.005

Tamioso PR, Maiolino Molento CF, Boivin X, Chandèze H, Andanson S, Delval É, Hazard D, da Silva GP, Taconeli CA, Boissy A (2018) Inducing positive emotions: Behavioural and cardiac responses to human and brushing in ewes selected for high vs low social reactivity. Appl. Anim. Behav. Sci. doi:10.1016/j.applanim.2018.08.001

Todorov A, Aviezer H (2018) Loud and unclear: untense ueal-uife uocalizations during affective situations are perceptually ambiguous and contextually malleable. Journal of experimental esychology doi: $10.1037 / x g e 0000535$

Veasey JS (2017) In pursuit of peak animal welfare; the need to prioritize the meaningful over the measurable. Zoo Biol doi:10.1002/zoo. 21390

Weary DM, Robbins JA (2019) Understanding the multiple conceptions of animal welfare. Anim. Welf. doi:10.7120/09627286.28.1.033

Westerath HS, Gygax L, Hillmann E (2014) Are special feed and being brushed judged as positive by calves ? Appl. Anim. Behav. Sci. doi:10.1016/j.applanim.2014.04.003

Widen SC, Russell JA (2010) Descriptive and prescriptive definitions of emotion. Emot. Rev. doi:10.1177/1754073910374667

Wiśniewska M, Janczarek I, Piwczyński D (2019) The Aging Phenomenon of Horses With Reference to Human-Horse Relations. J. Equine Vet. Sci. doi:10.1016/j.jevs.2018.11.005

Wookey O (2018) The Effect of the Brexit on Animal Welfare in the United Kingdom: A Case for Scepticism and Scrutiny. Derecho Anim. Forum Anim. Law Stud. doi:10.5565/rev/da.340 